\title{
General Introduction and Recovery Factors
}

By Mahendra K. Verma

Chapter A of

Three Approaches for

Estimating Recovery Factors in

Carbon Dioxide Enhanced Oil Recovery

Mahendra K. Verma, Editor

Scientific Investigations Report 2017-5062-A 


\title{
U.S. Department of the Interior RYAN K. ZINKE, Secretary
}

\section{U.S. Geological Survey William H. Werkheiser, Acting Director}

\author{
U.S. Geological Survey, Reston, Virginia: 2017
}

For more information on the USGS — the Federal source for science about the Earth, its natural and living resources, natural hazards, and the environment-visit https://www.usgs.gov or call 1-888-ASK-USGS.

For an overview of USGS information products, including maps, imagery, and publications, visit https://store.usgs.gov.

Any use of trade, firm, or product names is for descriptive purposes only and does not imply endorsement by the U.S. Government.

Although this information product, for the most part, is in the public domain, it also may contain copyrighted materials as noted in the text. Permission to reproduce copyrighted items must be secured from the copyright owner.

Suggested citation:

Verma, M.K., 2017, General introduction and recovery factors, chap. A of Verma, M.K., ed., Three approaches for estimating recovery factors in carbon dioxide enhanced oil recovery: U.S. Geological Survey Scientific Investigations Report 2017-5062, p. A1-A3, https://doi.org/10.3133/sir20175062A. 


\section{Contents}

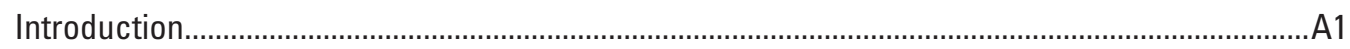

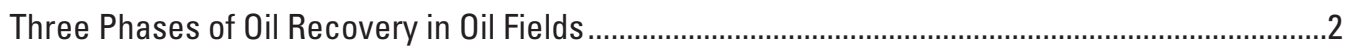

Three Approaches for Determining the Recovery Factor ............................................................

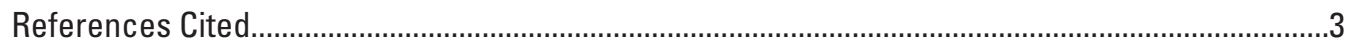





\title{
Chapter A. General Introduction and Recovery Factors
}

\author{
By Mahendra K. Verma'
}

\section{Introduction}

The U.S. Geological Survey (USGS) compared methods for estimating an incremental recovery factor for the carbon dioxide enhanced oil recovery $\left(\mathrm{CO}_{2}\right.$-EOR) process involving the injection of $\mathrm{CO}_{2}$ into oil reservoirs. In order to show the significance of the recovery factor $(R F)$, equation $\mathrm{A} 1$ relating the recoverable hydrocarbon volume with the $R F$ and various reservoir parameters is given below. Although the reservoir parameters used in equation $\mathrm{A} 1$ are generally known, the $R F$ for $\mathrm{CO}_{2}$-EOR is unknown for individual oil reservoirs and needs to be established for estimating the recoverable hydrocarbon volume. This chapter first provides some basic information on the $R F$, including its dependence on various reservoir and operational parameters, and then discusses the three development phases of oil recovery - primary, secondary, and tertiary (EOR). It ends with a brief discussion of the three approaches for estimating recovery factors, which are detailed in subsequent chapters.

For calculating technically recoverable hydrocarbon volumes from a volumetric approach, it is necessary to have the values of all the reservoir parameters that make up the volumetric equation, as given below:

recoverable $H C=R F\left[7758.4 \cdot \frac{A \times h \times \phi \times\left(1-S_{w i}\right)}{F V F_{o i l}}\right]$

where

$H C$ is the hydrocarbon volume, in stock tank barrels (STB);

$R F \quad$ is the recovery factor;

7758.4 is the conversion factor from acre-foot (acre-ft) to barrel (bbl);

$A$ is the area, in acres;

$h$ is the formation average net thickness, in feet;

$\phi \quad$ is the porosity, expressed as a fraction;

$S_{w i}$ is the initial or connate water saturation, expressed as a fraction; and

$F V F_{\text {oil }}$ is the formation volume factor for oil, in reservoir barrel per stock tank barrel of oil (bbl/STB).
The values of all the parameters except for the $R F$ are available from the comprehensive resource database (CRD) developed by INTEK Inc., a petroleum engineering consulting company under contract to the USGS (Carolus and others, in press). The data within the CRD are proprietary because they include field and reservoir properties from the "Significant Oil and Gas Fields of the United States Database" (NRG) from Nehring Associates Inc. (2012) and proprietary production and drilling data from IHS Inc. (2012). These proprietary data cannot be released directly to the public in this or other related reports.

The recovery factor for a reservoir is a function of lithology; porosity; rock permeability (including relative permeability of the fluids present in the reservoir); capillary size; rock wettability; oil properties such as oil gravity, viscosity, and percentage of medium to higher molecular weight components; and the reservoir driving mechanism in two types of oil reservoirs that are potentially suitable for $\mathrm{CO}_{2}$-EOR: (1) undersaturated oil reservoirs with or without aquifer support and (2) saturated oil reservoirs with a gas cap with or without aquifer support. The recovery factor may also be affected to some extent by other factors, such as using advanced technologies for drilling horizontal wells and multilateral wells and using more effectively the interpretation of production logs as well as seismic surveys. Of course, good reservoir management plays an important role in improving the recovery factor as managers continuously monitor the reservoir performance and proactively take measures to remedy various adverse operational situations.

Of the three approaches that are included in this report, the decline curve analysis and review of papers and reports on reservoirs with $\mathrm{CO}_{2}$-EOR do provide the $R F$ information for a certain number of reservoirs but do not help establish a technically sound basis for estimating recoverable hydrocarbon volumes for a large number of reservoirs. The third approach, reservoir simulation, is a proven and reliable procedure to estimate the $R F$ and hence help assess the technically recoverable hydrocarbon potential of all oil reservoirs that meet the screening criteria. 


\section{Three Phases of Oil Recovery in Oil Fields}

The history of an oil field may have three main developmental phases - primary, secondary, and tertiary recovery, also known as enhanced oil recovery (EOR) - all of which are intended to progressively improve the total recovery. Wells are drilled during the reservoir development phase, which is generally associated with the primary production phase when the reservoir is produced under its own energy that is manifested through the expansion of oil and rock with the decline in reservoir pressure. In conventional reservoirs (where oil is trapped due to the low permeability of an overlying formation), continued development calls for drilling more wells either as step-out wells or as in-fill wells to reduce the spacing among the existing wells. All these development wells accelerate the reservoir depletion rate, but the increase in the overall recovery factor depends on the permeability distribution and fluid properties of the individual reservoir. In unconventional reservoirs (where oil is trapped due to the ultralow permeability of the reservoir rock), additional wells are continually drilled to maximize the recoverable hydrocarbon volumes and thereby directly affect the recovery factor.

During the primary phase, oil production eventually declines to such a low level that the project becomes only marginally profitable, at which point, a secondary recovery phase is introduced. During this phase, either water is injected at the bottom of the reservoir structure or gas is injected at the top of the reservoir structure to raise the reservoir pressure, augmenting the reservoir energy for improved recovery. However, such injections are effective only if the reservoir has good horizontal and vertical permeability allowing gravity to keep the fluid segregated and resulting in higher displacement efficiency. In other places, where the geology is complex, the reservoir is produced with a waterflood on a line-drive or a normal or inverted five-spot, seven-spot, or nine-spot well pattern for better sweep efficiency and hence an improved recovery. During this phase, additional producers and injectors are drilled, and old wells are recompleted, worked over, or converted to either production or injection wells across the entire reservoir. In large reservoirs, the development is often carried out in phases.

At the end of the secondary phase, as the production begins to decline because of increasing water-cut or producing gas:oil ratio (GOR), the profitability once again becomes marginal. The decline in profitability may prompt the initiation of a tertiary phase, also called enhanced oil recovery (EOR). There are several EOR methods (chemical, thermal, and $\mathrm{CO}_{2}$ injection) for improving the oil recovery, but for the purpose of this study, the focus is on the $\mathrm{CO}_{2}$-EOR process. During the $\mathrm{CO}_{2}$-EOR phase, more wells may be drilled and existing wells recompleted or worked over depending on the well pattern for optimum recovery. Under $\mathrm{CO}_{2}$-EOR miscible conditions, theoretically oil recoveries could be as high as 90 percent of the oil in place in the $\mathrm{CO}_{2}$-swept region (Taber and others, 1997), but they are generally lower because of reservoir complexity in terms of lithology, structure, fractures, capillary pressure, rock wettability, oil viscosity and gravity, and permeability contrast between various zones in the reservoir. Application of economic filters to the $\mathrm{CO}_{2}$-EOR project further lowers the recovery factors.

\section{Three Approaches for Determining the Recovery Factor}

Due to the reliability and the ease of its use, reservoir simulation by $\mathrm{CO}_{2}$ Prophet was considered the preferred approach by the USGS for determining recovery factors for the $\mathrm{CO}_{2}$-EOR application in oil reservoirs within the United States. Two additional methods were considered valuable and were used to verify $R F$ values obtained from the simulationthe widely used empirical decline curve analysis (DCA) for estimating recoverable hydrocarbon volumes, and a review of published papers and reports on the performance of active or previously active $\mathrm{CO}_{2}$-EOR fields and reservoirs.

$\mathrm{CO}_{2}$ Prophet.-The $\mathrm{CO}_{2}$ Prophet model was developed for the U.S. Department of Energy by Texaco Inc. under contract DE-FC22-93BC14960 and was described by Dobitz and Prieditis (1994). Its application for reservoir simulation in this study is discussed in chapter B of this report.

Decline curve analysis. - Decline curve analysis is an empirical method and is used to estimate recoverable hydrocarbon volumes by analyzing the plots of the historical production rate against time or cumulative production from a reservoir. The $R F$ is determined by dividing the recoverable hydrocarbon volume with $\mathrm{CO}_{2}$-EOR method by the originaloil-in-place (OOIP) volume. This simple method for estimating the $R F$ is discussed in chapter $\mathrm{C}$ of this report.

Literature review.-A review of the publicly available literature has identified $53 \mathrm{CO}_{2}$-EOR projects in the United States and 17 abroad. The available information on $R F$ values from these 70 projects has been analyzed and is discussed in chapter D of this report.

Because the production data for the DCA are from either EOR pilot projects or portions of reservoirs, they pose a challenge for the estimation of oil-in-place values due to uncertainty in defining the area and (or) the layers within a reservoir affected by the EOR. Therefore, even with good values of ultimate production from DCA, there is a certain amount of uncertainty in the $R F$, which is a function of both the ultimate production and the oil-in-place values. The $R F$ values from a review of published papers and reports come from reservoirs with profitable $\mathrm{CO}_{2}$-EOR projects. Because of economic factors, they may be lower than $R F$ values obtained by $\mathrm{CO}_{2}$ Prophet for technically recoverable oil resources that are calculated as being producible by using current technology and industry practices without any economic constraint. 
However, the $R F$ values from DCA and from the review of published papers and reports will still help provide values of the $R F$ range, which will be useful in preparing a probabilistic estimate of technically recoverable oil volumes.

With the advancement of computer technology in terms of its affordability and the versatility of available models, reservoir simulation has become an invaluable tool to evaluate reservoir performance and recovery factors. Because $\mathrm{CO}_{2}$ Prophet models a simplified physical process occurring in the reservoir and does not capture the chemical processes that would be described by a sophisticated compositional model, it should not be expected to reflect all the subtleties of real-world petroleum operations. All three approaches will help to establish the range of recovery factors for various reservoir types and therefore are discussed in chapters B, C, and D.

\section{References Cited}

Carolus, Marshall, Biglarbigi, Khosrow, Warwick, P.D., Attanasi, E.D., Freeman, P.A., and Lohr, C.D., in press, Overview of a comprehensive resource database for the assessment of recoverable hydrocarbons produced by carbon dioxide enhanced oil recovery: U.S. Geological Survey Techniques and Methods, book 7, chap. C16.

Dobitz, J.K., and Prieditis, John, 1994, A steam tube model for the PC: SPE/DOE Ninth Symposium on Improved Oil Recovery, Tulsa, Oklahoma, 17-20 April 1994, paper SPE-27750-MS, 8 p.

IHS Inc., 2012, PIDM [Petroleum Information Data Model] relational U.S. well data [data current as of December 23, 2011]: Englewood, Colo., IHS Inc.

Nehring Associates Inc., 2012, Significant oil and gas fields of the United States database [data current as of December 2012]: Colorado Springs, Colo., Nehring Associates Inc.

Taber, J.J., Martin, F.D., and Seright, R.S., 1997, EOR screening criteria revisited-Part 1: Introduction to screening criteria and enhanced recovery field projects: SPE (Society of Petroleum Engineers) Reservoir Engineering, v. 12, no. 3 (August 1997), p. 189-198, paper SPE-35385-PA. 